\title{
LOWER AND UPPER ESTIMATES OF NUMERICAL SUMS
}

\author{
L. LEINDLER
}

Abstract. Some useful inequalities pertaining to lower and upper estimates of numerical series are improved. Moreover necessary and sufficient conditions are given that certain estimates be valid. Finally an application of the new inequalities is presented.

Mathematics subject classification (2000): 26D15, 26 A12.

Keywords and phrases: Inequalities for sums, quasi geometrically increasing (decreasing) sequences, weight functions.

\section{REFERENCES}

[1] A. Kufner, L. Maligranda And L. E. Persson, The Hardy Inequality. About its History and Some Related Results, Vydavatelski Servis Publishing House, Pilzen, 2007.

[2] L. LeINDLER, On the converses of inequality of Hardy and Littlewood, Acta Sci. Math. (Szeged), 58 (1993), 191-196.

[3] L. LEINDLER, Necessary and sufficient conditions for joint lower and upper estimates, J. Inequal. Pure Appl. Math., Volume 10 (2009), Issue 1, 6pp. (to appear).

[4] L. LEINDLER AND J. NÉMETH, On the connection between quasi power-monotone and quasi geometrical sequences with application to integrability theorems for power series, Acta Math. Hungar., 68, 1-2 (1995), 7-19. 